\title{
Synthetic coal fly ash-derived zeolites doped with silver nanoparticles for mercury
}

\section{(II) removal from water}

\author{
Z. Tauanova, P.E. Tsakiridis ${ }^{b}$, S.V. Mikhalovskyc and V.J.Inglezakis ${ }^{a}$ \\ a Environmental Science and Technology Group (ESTg), Chemical Engineering Department, School of \\ Engineering, Nazarbayev University, Astana, 010000, Kazakhstan \\ ${ }^{b}$ School of Mining and Metallurgical Engineering, National Technical University of Athens, Athens, Greece. \\ 'School of Pharmacy and Biomolecular Sciences, University of Brighton, UK \\ Corresponding author: vasileios.inglezakis@nu.edu.kz
}

\begin{abstract}
Coal fly ash-derived zeolites have attracted considerable interest in the last decade due to their use in several environmental applications such as the removal of dyes and heavy metals from aqueous solutions. In this work, coal fly ash-derived zeolites and silver nanoparticles-impregnated zeolites (nanocomposites) were synthesized and characterized by TEM/EDX, SEM/EDX, XRD, XRF, porosimetry (BET), particle size analysis (PSA) and zeta potential measurements. The synthesized materials were used for the removal of $\mathrm{Hg}^{2+}$ from aqueous solutions. The results demonstrated that nanocomposites can remove $99 \%$ of $\mathrm{Hg}^{2+}$, up to $10 \%$ and $90 \%$ higher than the removal achieved by the zeolite and the parent fly ash, respectively. Leaching studies further demonstrated the superiority of the nanocomposite over the parent materials. The $\mathrm{Hg}^{2+}$ removal mechanism is complex, involving adsorption, surface precipitation and amalgamation.
\end{abstract}


Keywords: Coal fly ash; synthetic zeolite; nanocomposites; silver nanoparticles; mercury removal; water treatment.

\section{Introduction}

Coal is one of the world's most abundant and widely spread fossil fuels, with global proven reserves accounting for nearly 1000 billion $\mathrm{Mg}$. It is still the most used type of fuel in many developing and developed countries such as South Africa (93\%), Poland (92\%), China (79\%), India (69\%) and the USA (49\%) (Bukhari et al., 2015). According to Yao et al. (2015) coal-fired electricity generation accounted for $29.9 \%$ of global electricity production in 2011 and it is projected to reach approximately $46 \%$ by 2030 . The top-ten countries that produce high amount of coal annually are China, USA, Russia, India, Germany, Poland, Indonesia, Australia, and South Africa; Kazakhstan rounds out the list with 120 million Mg/year (World Coal Institute, 2005). Coal consumption data reveal that nearly $5 \%$ of world coal consumption is by Eurasian states and Kazakhstan is amongst the three leading CIS states with a massive 22\% consumption (Bukhari et al., 2015).

Coal fly ash (CFA) is a by-product from combustion of coal in electric power stations. The amount of annually produced CFA is enormous and thus it requires attention and research on possible recycling routes as it can cause serious environmental and health problems (Blissett and Rowson, 2012; Franus et al., 2015). Several efforts have been undertaken globally to effectively reprocess this waste and convert it into value-added products, such as synthetic zeolites which find several applications in agriculture, medicine, industry and in environmental engineering such as the removal of heavy metals and other contaminants from water and gas purification (Franus, 2012; Jha and Singh, 2014; Tauanov et al., 2017; Wdowin et al., 2014a). Modified forms of CFA-derived synthetic zeolites and their composites with metals, metal oxides and hydroxides further expand the potential application fields (Goscianska et al., 2018; Zhang et al., 2018a; Zhang et al., 2018). 
There are several commonly applied methods for CFA conversion into zeolites, namely conventional hydrothermal synthesis, fusion-assisted hydrothermal synthesis, multi-step treatment, microwave-irradiation and sonication. All synthesis methods involve several steps of crystalline phase formation from amorphous CFA, including dissolution, condensation, nucleation and crystal growth (Bukhari et al., 2015). The advantage of conventional hydrothermal treatment is the simplicity of production, however it may produce a mixture of zeolites depending on reaction conditions, i.e. time, temperature, alkaline concentration, etc. Although the multi-step, microwave- and ultrasound-assisted methods produce single-phase zeolites faster and with high yields, they require high temperature treatment $(>773 \mathrm{~K})$, sonication for a certain duration or several steps, which entail additional costs (Belviso, 2017).

The contamination of water resources with heavy metals, particularly with $\mathrm{Hg}^{2+}$ and its species, is a serious global environmental threat. Mercury, due to its volatility, chemistry and bioaccumulation properties, is considered as one of the most toxic elements that severely affect human beings and the environment (Yu et al., 2016). According to current regulations of the US Environmental Protection Agency and the European Union the maximum concentration of mercury in drinking water is $2 \mathrm{mg} / \mathrm{m}^{3}$ and $1 \mathrm{mg} / \mathrm{m}^{3}$, respectively (AMAP/UNEP, 2013; The European Parlament and the Council of the European Union, 2013). A variety of methods for the removal of mercury from wastewater have been studied, including the application of electrochemical treatments (electrocoagulation, electroflotation, electrodeposition), physicochemical processes (chemical precipitation, ion exchange) and adsorption (activated carbon, carbon nanotubes, rice husk, etc.) (Azimi et al., 2017). Of all these methods adsorption by utilization of waste materials is of utmost interest, as is a low-cost and effective method for the treatment of polluted water and gases. There are numerous publications on the removal of elemental mercury from flue gas (Liu et al., 2018; Shao et al., 2016; Wdowin et al., 2015, 2014b; Yang et al., 2018), however limited studies were conducted on $\mathrm{Hg}^{2+}$ ions removal from water, particularly with utilization of CFA, synthetic 
zeolites and composites. Table 1 summarizes the adsorbents used for the removal of mercury from water and their efficiency. It should be noted that most of the experiments presented in Table 1 were carried out at $\mathrm{pH} 4.0$ or higher, which in combination to high mercury concentration may result in precipitates and insoluble complexes rendering the adsorption results questionable.

Table 1. Adsorbents for the removal of $\mathrm{Hg}^{2+}$ from aqueous phase

\begin{tabular}{|c|c|c|c|c|c|c|}
\hline Adsorbent type & $\begin{array}{c}\text { Initial } \\
\text { concentration of } \\
\mathrm{Hg}^{2+}\left[\mathrm{g} / \mathrm{m}^{3}\right]\end{array}$ & $\begin{array}{c}\text { Volume of } \\
\text { the } \mathrm{Hg}^{2+} \\
\text { solution } \\
{\left[\mathrm{cm}^{3}\right]}\end{array}$ & $\mathrm{pH}$ & $\begin{array}{l}\text { Adsorbent } \\
\text { dosage, }[\mathrm{g}]\end{array}$ & $\begin{array}{c}\text { Removal of } \\
\mathrm{Hg}^{2+}[\%]\end{array}$ & References \\
\hline $\begin{array}{l}\text { Activated carbon from } \\
\text { organic sewage sludge }\end{array}$ & 200 & 100 & 5.0 & $4-10$ & $83-100$ & $\begin{array}{l}\text { (Zhang et } \\
\text { al., 2005) }\end{array}$ \\
\hline Weathered coal & 3 & 100 & 6.0 & 0.8 & $>99$ & $\begin{array}{l}\text { (Meena et } \\
\text { al., 2004) }\end{array}$ \\
\hline $\begin{array}{l}\text { Chitosan-coated } \\
\text { Magnetite nanoparticles }\end{array}$ & 6.2 & 50 & 5.0 & 0.67 & $>99$ & $\begin{array}{l}\text { (Rahbar et } \\
\text { al., 2014) }\end{array}$ \\
\hline $\mathrm{Ag} /$ graphene & 100 & 100 & 5.0 & 0.1 & 98 & $\begin{array}{c}\text { (Qu et al., } \\
\text { 2017) }\end{array}$ \\
\hline $\begin{array}{l}\text { Ornamental rock solid } \\
\text { waste }\end{array}$ & 10 & 125 & $2-8$ & 2 & $>90$ & $\begin{array}{l}\text { (Dos } \\
\text { Santos et } \\
\text { al., 2015) }\end{array}$ \\
\hline $\begin{array}{l}\text { Flower-like titanate } \\
\text { nanomaterial }\end{array}$ & 100 & 50 & 5.0 & 0.01 & 98 & $\begin{array}{l}\text { (Liu et al., } \\
\text { 2015) }\end{array}$ \\
\hline $\begin{array}{l}\text { Linde Type A CFA derived } \\
\text { zeolite }\end{array}$ & 10 & 10 & 2.5 & $0.1-1.0$ & 94 & $\begin{array}{l}\text { (Attari et } \\
\text { al., 2017) }\end{array}$ \\
\hline ZSM-5-mesoporous/HAPT & 2 & 100 & $2-12.5$ & 0.02 & 94 & $\begin{array}{l}\text { (Abbas et } \\
\text { al., 2018) }\end{array}$ \\
\hline Ag-X CFA derived zeolite & $13.2-575$ & 100 & $5-6$ & 10 & 90 & $\begin{array}{c}\text { (Czarna et } \\
\text { al., 2016) }\end{array}$ \\
\hline
\end{tabular}

Among the several metal and metal-oxide containing composites silver and silver oxide nanoparticles (NPs) containing zeolite composites have attracted considerable attention owing to the unique property of silver to form amalgam with mercury. Although some other noble metals also form amalgams they are considerably more expensive than silver. There are some studies on utilization of zeolites derived from CFA for mercury removal, however the research on NPimpregnated CFA-derived zeolites for the removal of mercury from aqueous and gaseous phases is 
very limited. In this paper the synthesis of CFA-derived zeolites and novel silver NPs-impregnated zeolite nanocomposites is presented, along with full characterization of the derived materials and a study on the removal of $\mathrm{Hg}^{2+}$ from aqueous solutions. Moreover, a possible mechanism of the mercury removal by the nanocomposite material is proposed.

\section{Materials and methods}

\subsection{Materials and synthesis}

The CFA used in the present study is derived from the electrostatic precipitators of Oskemen city power plant (Karazhyra CFA, East Kazakhstan, $252 \mathrm{MW}$ ) and labelled as K-CFA. All chemical reagents used were of analytical grade. Synthetic zeolites (K-ZFA) were produced through a conventional hydrothermal alkaline treatment of K-CFA at $383 \mathrm{~K}$, in a 1-dm ${ }^{3}$ heavy-walled thermal and chemical resistant reactor using $3 \mathrm{~mol} / \mathrm{dm}^{3}$ aqueous $\mathrm{NaOH}$ (Sigma-Aldrich) as an activation agent. The stirring speed was kept constant at $125 \mathrm{rpm}$, while an incubation period of $48 \mathrm{~h}$ was selected in all cases after which the final mixtures were filtered and washed several times for the removal of excess $\mathrm{NaOH}$. The solid residues were dried at $343 \mathrm{~K}$ overnight and the products obtained were stored in a tightly closed container for characterization and further experiments.

The K-ZFA was then loaded with silver nanoparticles (Ag NPs) to obtain the nanocomposite materials used for mercury removal from aqueous solutions. The Ag NPs impregnation into the structure of zeolites consisted of two main steps: ion exchange and reduction. Initially, zeolite samples were fully dried at $573 \mathrm{~K}$ for $3 \mathrm{~h}$ to remove any remaining water molecules in their structure. Then, a slightly modified ion-exchange reaction was conducted by mixing $10 \mathrm{~cm}^{3}$ of 0.01 $\mathrm{mol} / \mathrm{cm}^{3}$ aqueous solution of $\mathrm{AgNO}_{3}$ (Sigma-Aldrich) with $1 \mathrm{~g}$ of zeolite and left to react for $12 \mathrm{~h}$ (Golubeva et al., 2013). Finally, the obtained Ag-exchanged zeolite slurry was dried at $403 \mathrm{~K}$ for 3 h. The obtained $\mathrm{Ag}^{+}$-ZFA was then annealed for $3 \mathrm{~h}$ at $773 \mathrm{~K}$, followed by $4 \mathrm{~h}$ of silver ions reduction using $\mathrm{NaBH}_{4}$ as the reducing agent, thus producing nanocomposites with various Ag NPs 
loadings (Ag-ZFA). The reaction container was covered with aluminium foil and stored in dark place to prevent oxidation of silver ions. The same procedure was carried out without adding $\mathrm{AgNO}_{3}$ solution (R-ZFA) to investigate the effect of reduction on the zeolite structure.

\subsection{Characterization of materials}

Chemical analysis of both fly ash and produced zeolites, with and without Ag NP impregnation, was done using X-Ray fluorescence (XRF, PANalytical). Their mineralogical composition was identified by X-Ray diffraction (XRD) using a Bruker D8-Focus diffractometer with Ni-filtered CuKa radiation $\left(k=1.5406 \mathrm{~A}^{\circ}\right)$, at $40 \mathrm{kV}$ and $40 \mathrm{~mA}$. The morphological characteristics of the materials were studied by using Scanning Electron Microscopy (SEM) on JEOL 6380LV Scanning Electron Microscope, operating in LV mode at $20 \mathrm{kV}$ equipped with a backscattered electron detector. Spot and area analyses were carried out using a $\mathrm{Si}(\mathrm{Li})$ Energy-Dispersive X-ray spectrometer (INCA Xsight, Oxford Instruments) connected to SEM. The nanoscale investigation was performed with a high-resolution JEOL JEM-2100 LaB 6 transmission electron microscope (HRTEM), operating at 200 $\mathrm{kV}$. The samples ( $0.2 \mathrm{~g})$ were suspended in alcohol and treated with ultrasound to disaggregate the agglomerated particles. A drop from the suspension was then placed on a 300 -mesh carbon coated copper grid and air-dried overnight. The grain microstructure was also studied using a bright field detector in scanning (STEM) mode. Elemental analysis was carried out using an Oxford X-Max 100 Silicon Drift Energy Dispersive X-ray spectrometer connected to TEM, with a probe size ranging from 2 to $5 \mathrm{~nm}$ in STEM mode. The porous structure was determined using low temperature nitrogen adsorption measured on Autosorb-1 porosimeter (Quantochrome, UK). The average pore size and total pore volume were calculated from the experimental data using the inbuilt software. The specific surface area (SSA) was calculated using the BET equation. The particle size distribution (PSD) was derived using a particle size analyzer in the wet dispersion mode 
(Malvern Mastersizer 3000). The zeta-potential at different $\mathrm{pH}$ values (from 2 to 12) was studied using a Zetasizer (Malvern Zetasizer Nano ZS).

\subsection{Batch adsorption kinetics}

A volume of $100 \mathrm{~cm}^{3}$ of $10 \mathrm{~g} / \mathrm{m}^{3} \mathrm{Hg}^{2+}$ solution at $\mathrm{pH} 2.0$ was mixed with $0.75 \mathrm{~g}$ of solids in a batch reactor without agitation at room temperature. The initial adjustment of $\mathrm{pH}$ was done with $\mathrm{HNO}_{3}$. The mercury solutions were prepared by dissolving analytical grade $\mathrm{HgCl}_{2}$ in ultra-pure water. After certain time intervals, $0.1 \mathrm{~cm}^{3}$ of samples were taken from adsorption containers for analysis. The total sampling volume was kept lower than $2 \%$ of initial volume in all experiments. A mercury analyzer (RA-915 $\mathrm{M}$ by Lumex) with a pyrolysis technique and detection limit of $1 \mathrm{mg} / \mathrm{m}^{3}$ for a sampling volume of $0.01-0.2 \mathrm{~cm}^{3}$ was used for the determination of total mercury. Two blanks were used; one with the same initial concentration of mercury and volume without solids and the second with deionized water with solids. Blank experiments showed that the $\mathrm{Hg}^{2+}$ losses due to adsorption on container walls and/or volatilization are limited to an average of $6.5 \%$. All experiments were carried out in duplicate and the average standard deviation was $1.3 \%$.

\subsection{Leaching experiments}

The retention of $\mathrm{Hg}^{2+}$ ions after adsorption on the solids was studied by running leaching experiments under strong acidic $(\mathrm{pH} 2.0)$ and neutral $(\mathrm{pH} 7.0)$ conditions. The amount of $0.75 \mathrm{~g}$ of each adsorbent was placed in a container filled with $50 \mathrm{~cm}^{3} \mathrm{Hg}^{2+}$ solution with initial concentration of $150 \mathrm{~g} / \mathrm{m}^{3}$. The tightly closed containers were left for 6 days without any stirring at room temperature. After that, all samples were filtered, thoroughly washed with deionized water until neutral $\mathrm{pH}$ and dried in a vacuum oven at $70^{\circ} \mathrm{C}$. The dried adsorbents were divided and placed into two separate containers for the leaching experiments: one container with $0.3 \mathrm{~g}$ adsorbent was 
filled with $50 \mathrm{~cm}^{3}$ deionized water at $\mathrm{pH} 2$ and the other container with $50 \mathrm{~cm}^{3}$ deionized water, at $\mathrm{pH}$ 4. The initial $\mathrm{pH}$ adjustment was done with $\mathrm{HNO}_{3}$. The samples were withdrawn after 6 and 12 d from each container and analyzed for leached $\mathrm{Hg}^{2+}$ ions. All the leaching experiments were carried out in duplicate.

\subsection{Adsorption capacity}

Samples of K-ZFA and Ag-ZFA were studied by the method of repeated batch equilibrations in order to estimate the maximum adsorption under the studied concentration of $10 \mathrm{~g} / \mathrm{m}^{3}$. A measured quantity of zeolite $(0.25 \mathrm{~g})$ was added to a container with known volume $\left(50 \mathrm{~cm}^{3}\right)$ and concentration $\left(10 \mathrm{~g} / \mathrm{m}^{3}\right)$ of $\mathrm{Hg}^{2+}$ solutions at room temperature. The initial $\mathrm{pH}$ was adjusted to 2.0 and aliquots for mercury analysis were sampled after $3 \mathrm{~d}$. Then, the old solution was replaced with freshly prepared $\mathrm{Hg}^{2+}$ solution with the same concentration, volume and $\mathrm{pH}$ until no further uptake from the materials was observed (Inglezakis et al., 2002).

\section{Results and discussion}

\subsection{Synthesis and Characterization}

The chemical composition of the initial K-CFA and the produced zeolitic material K-ZFA are presented in Table 2 . K-CFA mainly contains silicon and aluminium (a total of 75 wt.\%), with a Si/Al ratio of about 1.65 . This observation together with the low content of $\mathrm{CaO}(2.8 \mathrm{wt} \%), \mathrm{MgO}(0.7$ wt\%) and $\mathrm{SO}_{3}(0.2 \mathrm{wt} . \%)$ is indicative of the bituminous coal source burning (type $\mathrm{F}$ ). The $\mathrm{Fe}_{2} \mathrm{O}_{3}$ concentration is relatively high, reaching 16 wt.\%. K-ZFA contained higher amount of $\mathrm{Na}_{2} \mathrm{O}$ than KCFA because of the hydrothermal treatment with sodium hydroxide solution, whereas at the same time the initial $\mathrm{K}_{2} \mathrm{O}$ content in CFA (1.3 wt.\%) was diminished as it was replaced by sodium ions, 
reaching 0.12 wt.\%. The silver impregnation in the zeolite structure is evident and its concentration reached 5 wt\%.

Table 2. Chemical composition CFA and Zeolites ${ }^{a}$, wt.\%

\begin{tabular}{|c|c|c|c|}
\hline \multirow{2}{*}{ Compounds } & \multicolumn{3}{|c|}{ Material type } \\
\hline & K-CFA & K-ZFA & $\mathrm{Ag}-\mathrm{ZFA}$ \\
\hline $\mathrm{Na}_{2} \mathrm{O}$ & 0,678 & 4,447 & 3,405 \\
\hline $\mathrm{MgO}$ & 0,716 & 0,708 & 0,646 \\
\hline $\mathrm{Al}_{2} \mathrm{O}_{3}$ & 25,761 & 30,888 & 28,245 \\
\hline $\mathrm{SiO}_{2}$ & 49,802 & 32,488 & 30,959 \\
\hline $\mathrm{SO}_{3}$ & 0,237 & 0,086 & 0,047 \\
\hline $\mathrm{K}_{2} \mathrm{O}$ & 1,324 & 0,15 & 0,119 \\
\hline $\mathrm{CaO}$ & 2,798 & 2,39 & 2,089 \\
\hline $\mathrm{TiO}_{2}$ & 1,636 & 1,258 & 1,142 \\
\hline $\mathrm{Cr}_{2} \mathrm{O}_{3}$ & 0,033 & 3,104 & 3,359 \\
\hline $\mathrm{MnO}$ & 0,216 & 0,411 & 0,463 \\
\hline $\mathrm{Fe}_{2} \mathrm{O}_{3}$ & 16,076 & 23,066 & 22,389 \\
\hline $\mathrm{CO}_{3} \mathrm{O}_{4}$ & 0,028 & 0,061 & 0,06 \\
\hline $\mathrm{NiO}$ & 0,032 & 0,432 & 0,383 \\
\hline $\mathrm{CuO}$ & 0,042 & 0,028 & 0,025 \\
\hline ZnO & 0,052 & 0,04 & 0,033 \\
\hline $\mathrm{SrO}$ & 0,195 & 0,206 & 0,167 \\
\hline $\mathrm{Y}_{2} \mathrm{O}_{3}$ & 0,012 & 0,013 & 0,018 \\
\hline $\mathrm{ZrO}_{2}$ & 0,06 & 0,074 & 0,07 \\
\hline $\mathrm{Ag}_{2} \mathrm{O}$ & 0 & 0 & 5.056 \\
\hline $\mathrm{BaO}$ & 0,143 & 0,119 & 0,109 \\
\hline $\mathrm{CeO}_{2}$ & 0,126 & 0 & 0,055 \\
\hline $\mathrm{Cl}$ & 0,026 & 0,03 & 0 \\
\hline
\end{tabular}

${ }^{\mathrm{a}}$ The results of analysis are presented for elements as oxides

The mineralogical composition of both K-CFA and K-ZFA produced is presented in the corresponding XRD patterns of Fig. 1. Regarding K-CFA, three major phases were identified: mullite $\left(3 \mathrm{Al}_{2} \mathrm{O}_{3} \cdot 2 \mathrm{SiO}_{2}\right)$, quartz $\left(\mathrm{SiO}_{2}\right)$ and spinel magnetite $\left(\mathrm{FeOFe}_{2} \mathrm{O}_{3}\right)$, in which other oxides such as $\mathrm{Mg}$, $\mathrm{Mn}, \mathrm{Ca}$ or Si oxides, are found as inclusions. 


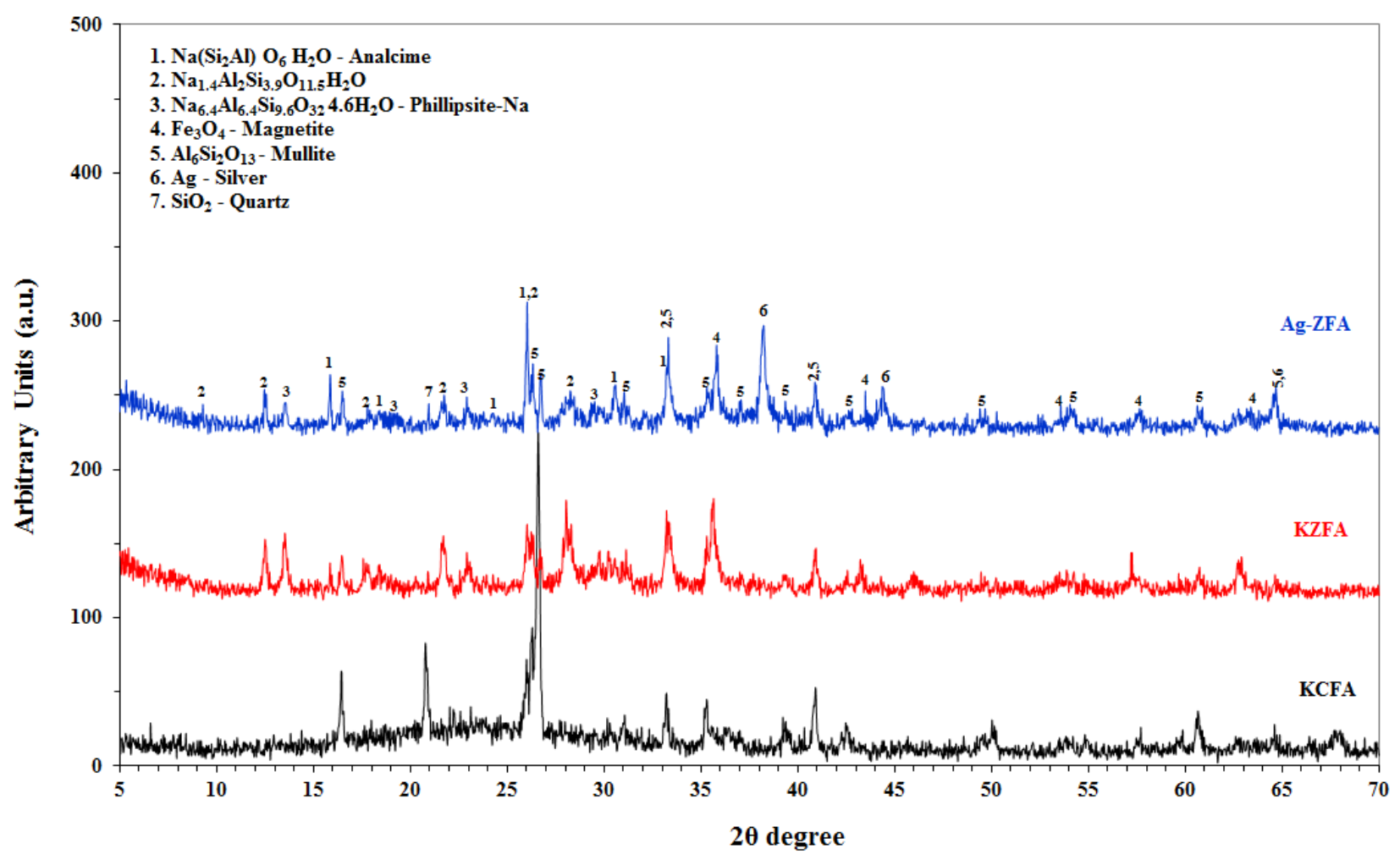

Fig. 1. XRD spectra of K-CFA, K-ZFA and Ag-ZFA

A substantial amount of an amorphous matrix in the K-CFA sample (due to relatively rapid cooling) was observed in the range of $15^{\circ}-35^{\circ}$, where the glassy phase is revealed through the characteristic diffused wide band. In case of the zeolites, it is obvious that during the hydrothermal process two new zeolitic phases were developed. Analcime was observed as the major phase, whereas phillipsite-Na was also present as the minor zeolite. Simultaneously the content of mullite and quartz has been significantly decreased mainly due to their partial dissolution and the consequent zeolite phases growth. The spectra obtained for the nanocomposite Ag-ZFA confirmed the presence of the metallic Ag NPs in the zeolitic matrix, by the characteristic peaks of silver at $38.18^{\circ}, 44.33^{\circ}$ and $64.52^{\circ}$.

The zeolification process and the zeolite crystal development on the fly ash particles were also observed under the scanning electron microscope. The corresponding micrographs of Fig. 2 
revealed that the initial fly ash was predominantly granular and spherical in shape, with the particle size in the range from 5 to $30 \mu \mathrm{m}$.

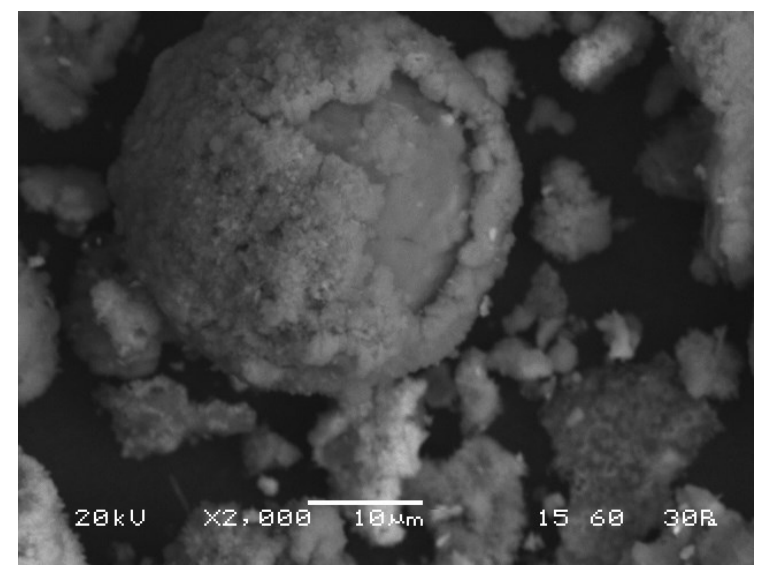

K-ZFA

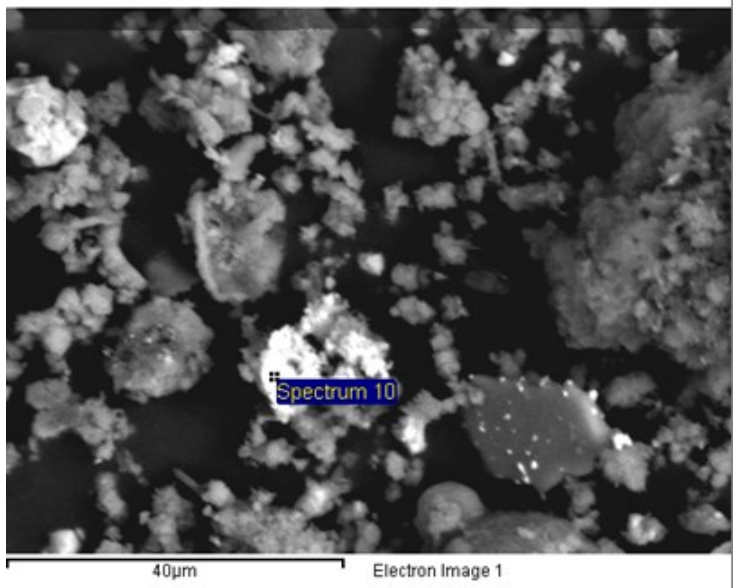

Ag-ZFA

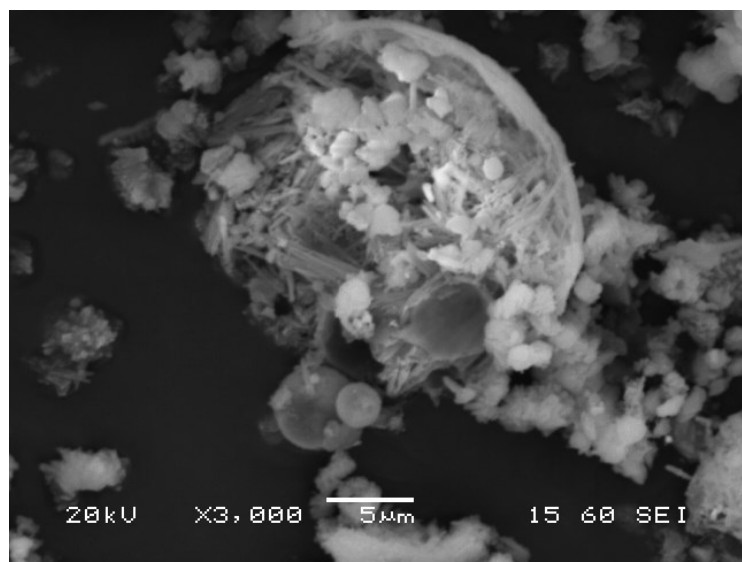

K-ZFA

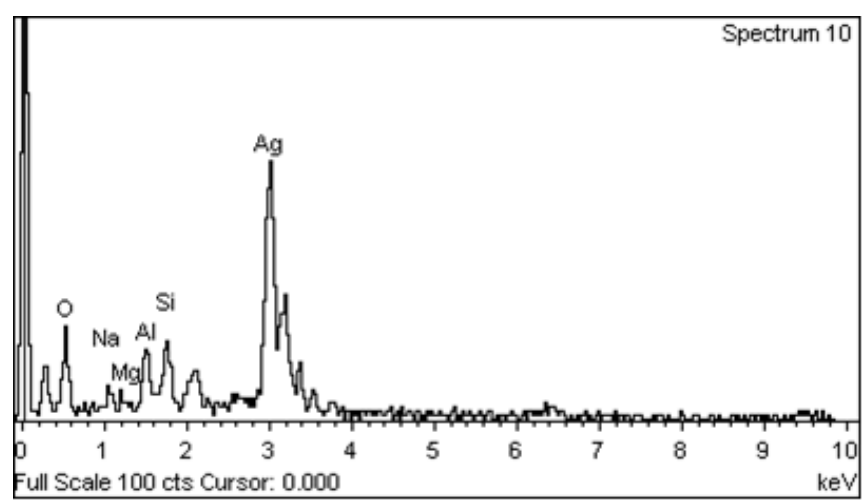

Ag-ZFA

Fig. 2. SEM image of the K-ZFA crystal growth and SEM/EDX analysis of Ag-ZFA

The aluminosilicate and silicate compounds (mullite, amorphous glass and quartz) acted as the substrate for the zeolitic phases growth and transformed into sodium aluminates and silicates. They provided the required nucleation sites for zeolite evolution and led to the partial development of needle-like or fibrous Na-P1 zeolite on and inside the fly ash spheres, with an approximate length of 1-2 $\mu \mathrm{m}$. The high $\mathrm{Na}^{+}$concentration seems to have acted as the stabilizer of the sub-micron building units of the forming zeolite crystalline structure. The detection of finer configurations could be attributed to the presence of small amount of amorphous or sodalite 
nature formations, during zeolitic transformation with lower Al content. On the other hand, the presence of Ag NPs in the zeolitic samples did not significantly affect their structure. No metallic silver agglomeration was observed, indicating a uniform matrix with well dispersed metallic particles of silver.

The presence of metallic silver detected by XRD analysis, was also corroborated by Transmission Electron Microscopy imaging. Fig. 3 shows the TEM images of ZFA after impregnation with silver NPs. The metallic silver NPs can be observed well dispersed in the zeolitic matrix, with low degree of agglomeration, ranging from 5 to $40 \mathrm{~nm}$. In most cases the particles are well defined and spherical with an average size of $10 \mathrm{~nm}$. The EDX elemental composition analysis also confirmed the presence of silver.
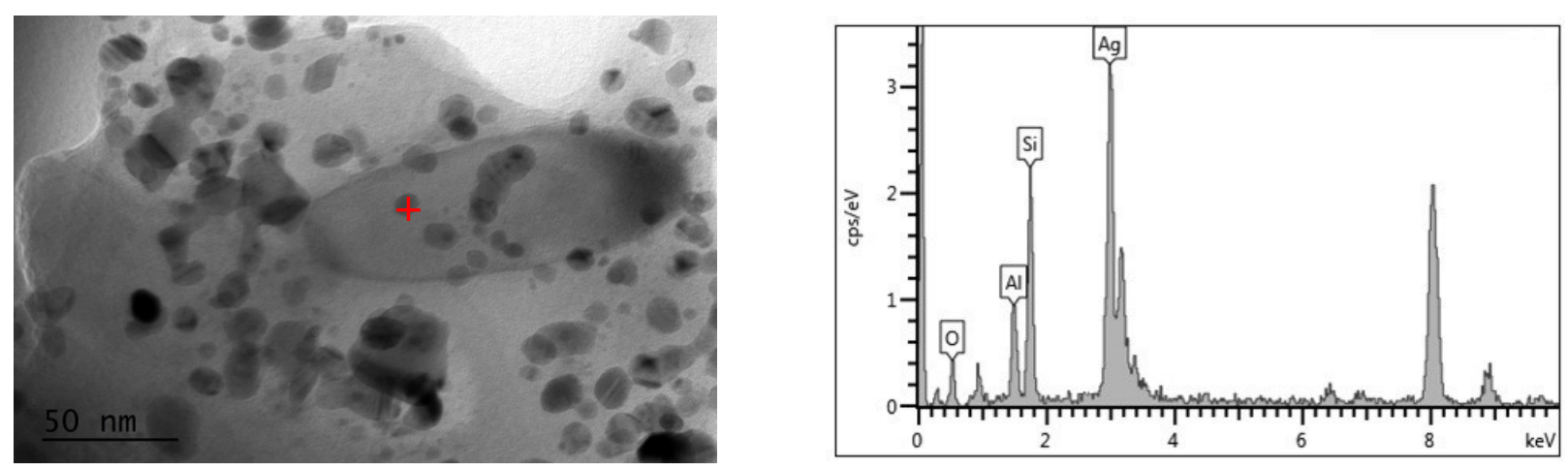

Fig. 3. TEM/EDX analysis of Ag-ZFA

The results of BET analysis (Table 3 ) show, as expected, that the initial raw CFA had the lowest specific surface area. It is widely known that synthetic zeolites produced from CFAs have a surface area ranging from 40 to $260 \mathrm{~m}^{2} / \mathrm{g}$ possessing a microporous structure (Derkowski et al., 2006; Wang et al., 2015; Wdowin et al., 2014b). The resulting surface areas are in general agreement with he published values and SSA of the K-ZFA reached a maximum of $56 \mathrm{~m}^{2} / \mathrm{g}$. The Ag-ZFA, on the other hand, showed a considerable increase of BET surface area reaching a maximum of $105 \mathrm{~m}^{2} / \mathrm{g}$, which is attributed to the effect of Ag NPs impregnated in the zeolite microstructure that 
facilitated the surface enhancement. The SSA of spherical Ag NPs with the size of $5 \mathrm{~nm}$ is ca. 2 $\mathrm{m}^{2} / \mathrm{g}$, assuming their density is equal to the density of the bulk silver $\left(10.49 \mathrm{~g} / \mathrm{cm}^{3}\right)$. Therefore, the SSA enhancement in the presence of Ag NPs has a more complex origin. The reduced zeolite (RZFA) has about $64 \%$ lower specific surface area that can be attributed to the effect of the elevated temperature during annealing, which probably led to destruction of the initial finer pore structure and a shift to wider pore sizes.

Table 3. BET surface areas of materials

\begin{tabular}{lccc}
\hline Material type & $\begin{array}{c}\text { BET surface area, } \\
\mathrm{m}^{2} / \mathrm{g}\end{array}$ & $\begin{array}{c}\text { Average pore size, } \\
\mathrm{nm}\end{array}$ & $\begin{array}{c}\text { Total pore volume, } \\
\mathrm{cm}^{3} / \mathrm{g}\end{array}$ \\
\hline K-CFA & $18 \pm 15$ & $10 \pm 2.0$ & $0.04 \pm 0.02$ \\
K-ZFA & $56 \pm 12$ & $14 \pm 0.2$ & $0.25 \pm 0.01$ \\
R-ZFA & $38 \pm 8.0$ & $15 \pm 0.1$ & $0.16 \pm 0.09$ \\
Ag-ZFA & $105 \pm 12$ & $15 \pm 3.9$ & $0.22 \pm 0.07$ \\
\hline
\end{tabular}

The results of the particle size distribution analysis (PSD) are presented in Table 4. Both R-ZFA and Ag-ZFA exhibited a lower average grain size than K-CFA and K-ZFA. In K-ZFA samples 90 wt.\% of the particles have sizes smaller than $65.8 \mu \mathrm{m}$, with 50 wt.\% of it below $25.5 \mu \mathrm{m}$. The corresponding values in Ag-ZFA were at $55.7 \mu \mathrm{m}$ and $13.2 \mu \mathrm{m}$, respectively. This result could be attributed to the agglomeration phenomena of the finer particles of the as produced zeolite, which have been eliminated after annealing, mainly due to the removal of crystalline water at higher temperatures. This could affect the loading kinetics, as the adsorption rate is faster when the particle size is smaller.

Table 4. PSD analysis of materials

\begin{tabular}{llccc}
\hline PSD & K-CFA & K-ZFA & Ag-ZFA & R-ZFA \\
\hline $\operatorname{Dv}(10), \mu \mathrm{m}$ & $22.0 \pm 2.4$ & $5.7 \pm 0.3$ & $2.44 \pm 0.01$ & $1.75 \pm 0.05$ \\
$\operatorname{Dv}(50), \mu \mathrm{m}$ & $57.4 \pm 0.03$ & $25.5 \pm 0.8$ & $13.2 \pm 0.02$ & $8.04 \pm 0.03$ \\
$\operatorname{Dv}(90), \mu \mathrm{m}$ & $161 \pm 5.7$ & $65.8 \pm 0.8$ & $55.7 \pm 0.05$ & $41.5 \pm 4.4$ \\
\hline
\end{tabular}




\subsection{Adsorption kinetics}

In the course of kinetic experiments $\mathrm{pH}$ increased from 2.0 to 3.5 for the K-CFA and around 6.25 for the rest of samples while the conductance decreased from $2680 \mu \mathrm{S} / \mathrm{cm}$ to $840 \mu \mathrm{S} / \mathrm{cm}$ for K-CFA and to ca. $750 \mu \mathrm{S} / \mathrm{cm}$ for the rest of the samples. Approximately the same final $\mathrm{pH}$ and conductance values were observed for the K-ZFA reference reactors, i.e. K-ZFA in ultra-pure water. Thus, the drop in the conductance can be attributed to cation exchange mostly between $\mathrm{H}^{+}$in the solution and $\mathrm{Na}^{+}$on the surface owing to the significant difference in their conductivities, which is $34.96 \mathrm{mS} \mathrm{m} / 2 / \mathrm{mol}$ and $5.01 \mathrm{mS} \mathrm{m} 2 / \mathrm{mol}$ at $298 \mathrm{~K}$, respectively (Atkins and Paula, 2009).

According to the adsorption kinetics results, Ag-NPs containing composite reached an equilibrium removal of $99 \%$ in just one day, ZFA $91.3 \%$ in 14 days, R-ZFA $77.5 \%$ in 21 days and the lowest removal was demonstrated by CFA, $9.7 \%$ reached in 29 days. Thus, both the removal rate and maximum removal at equilibrium follow the same order: Ag-ZFA > K-ZFA > R-ZFA >> K-CFA (Fig. 4). This order correlated with the BET surface area order of the materials, demonstrating adsorption as the predominant removal mechanism.

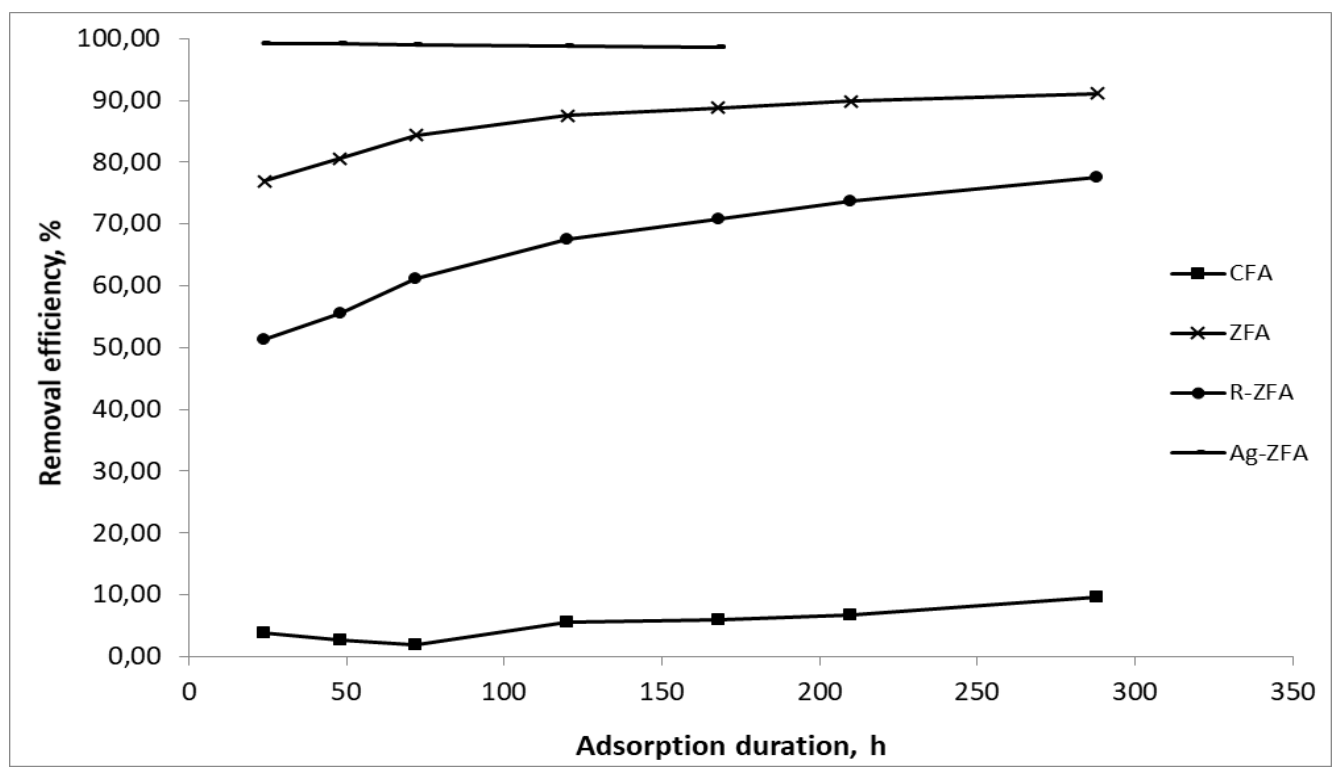

Fig. 4. Adsorption kinetics of $\mathrm{Hg}^{2+}$ from aqueous solutions. 
As it is shown PSD analysis the average particle size of the nanocomposite is lower than this of the zeolite, which contributes to very high adsorption rates in the former. Note that even though RZFA has the smallest particle size it demonstrates much slower kinetics in comparison with Ag-ZFA, which shows that the adsorption rate is not determined by the particle size alone. Thus, surface area and particle size alone cannot explain the results. Another contributing factor could be the result of the redox reactions between $\mathrm{Ag}^{\circ} / \mathrm{Ag}^{+}\left(+0.80 \mathrm{~V}\right.$ ) and $\mathrm{Hg}^{2+} / \mathrm{Hg}^{\circ}$ (+0.85 V) (Henglein and Brancewicz, 1997; Sumesh et al., 2011). In this work, we support the hypothesis that there are three co-existing mechanisms, namely surface adsorption, $\mathrm{Hg}^{2+}$ reduction to $\mathrm{Hg}^{\circ}$ followed by surface precipitation and formation of the silver amalgam or alloy $\left(\mathrm{Ag}_{\mathrm{x}} \mathrm{Hg}_{\mathrm{y}}\right)$. Several studies conducted in the field of selective sensors for the detection of $\mathrm{Hg}$ using Ag NPs-containing substrates report amalgamation reactions between the two metals (Deng et al., 2015; Panichev et al., 2014). Furthermore, the study of Pang and Ritchie (1982) describes two different mechanisms, namely dissolution and displacement reactions, where the precipitated mercury amalgamates with the precipitated silver.

As shown in Fig. 5, a distinctive decrease of $\mathrm{Ag}$ NP major peaks and formation of $\mathrm{AgCl}$ on XRD of Ag-ZFA after adsorption with $10 \mathrm{~g} / \mathrm{m}^{3} \mathrm{HgCl}_{2}$ solution was observed, which supports this hypothesis. The Ag NP peak disappearance upon interaction with mercury was also observed by Sumesh et al. (2011), where the authors revealed the formation of paraschachnerite $\mathrm{Ag}_{3} \mathrm{Hg}_{2}$ that has an orthorhombic crystal structure. The $\mathrm{Hg}^{2+}$ reduction and amalgamation were also observed by Henglein and Brancewicz (1997) and Henglein (1998) and who suggested the following reactions $\mathrm{Hg}^{2+}$ and $\mathrm{Ag}$ NPs:

$$
\begin{gathered}
\mathrm{Ag}_{m}+(m / 2) \mathrm{Hg}^{2+} \rightarrow{ }_{m} \mathrm{Ag}^{+}+(m / 2) \mathrm{Hg} \\
\mathrm{Ag}_{n}+\mathrm{Hg}^{2+} \rightarrow \mathrm{Ag}_{(n-2)} \mathrm{Hg}+2 \mathrm{Ag}^{+}
\end{gathered}
$$




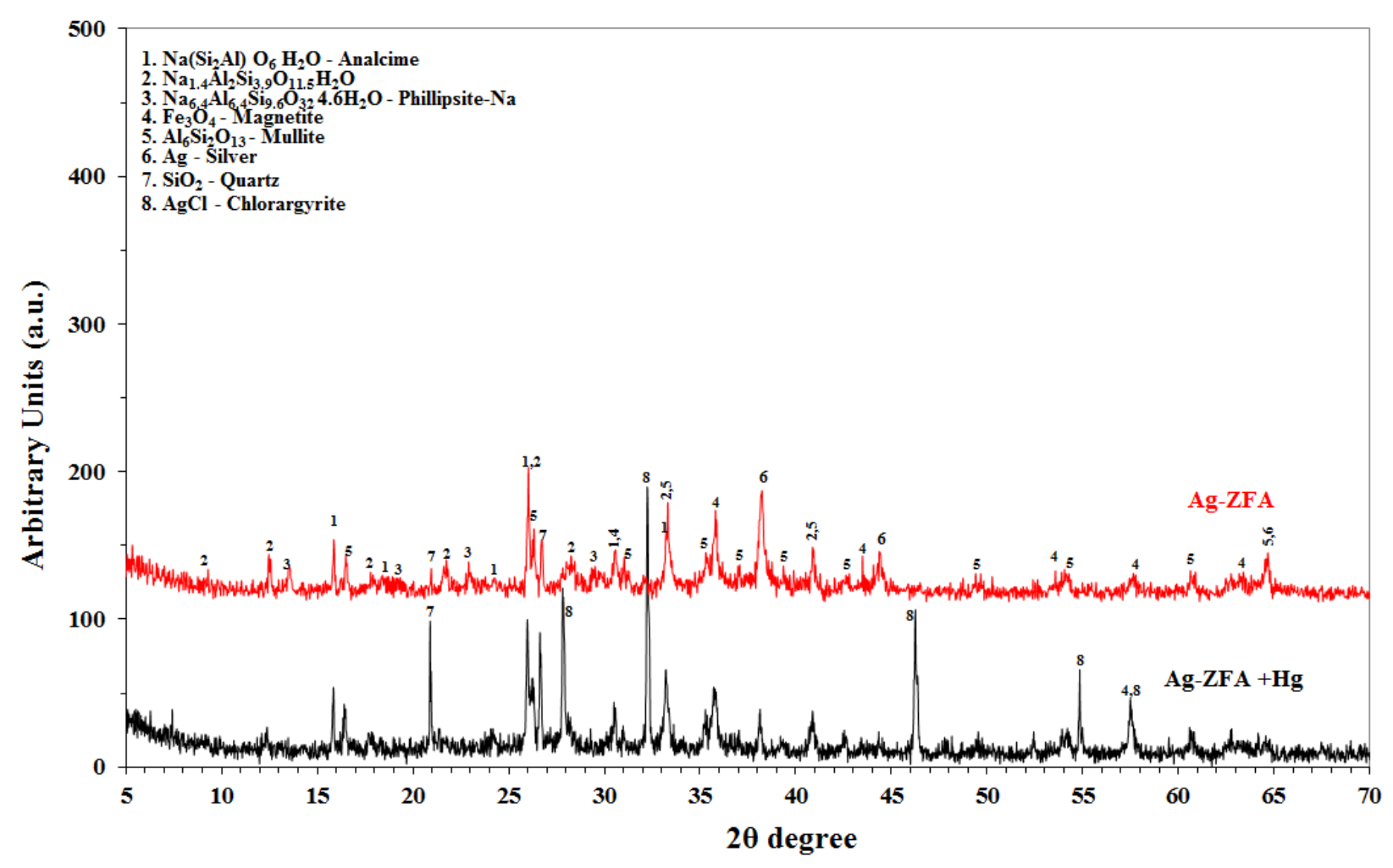

Fig. 5. XRD spectra of ZFA and Ag-ZFA with $\mathrm{Hg}$ (II)

The study of the samples loaded with mercury under the TEM (Fig. 6 and 7) revealed the nature of the new formation. In case of samples loaded with mercury, the metallic Ag particles have been significantly reduced in quantity and in size, presenting a distribution with an average size of 10-20 nm. Mercury, except being absorbed and bound in the zeolite matrix, was also detected as metallic $\mathrm{Hg}$, always coexisting with $\mathrm{Ag}$, presenting fluid formations, not dispersed but mainly agglomerated, developing dark long fibrils or non-transmitted large spots.
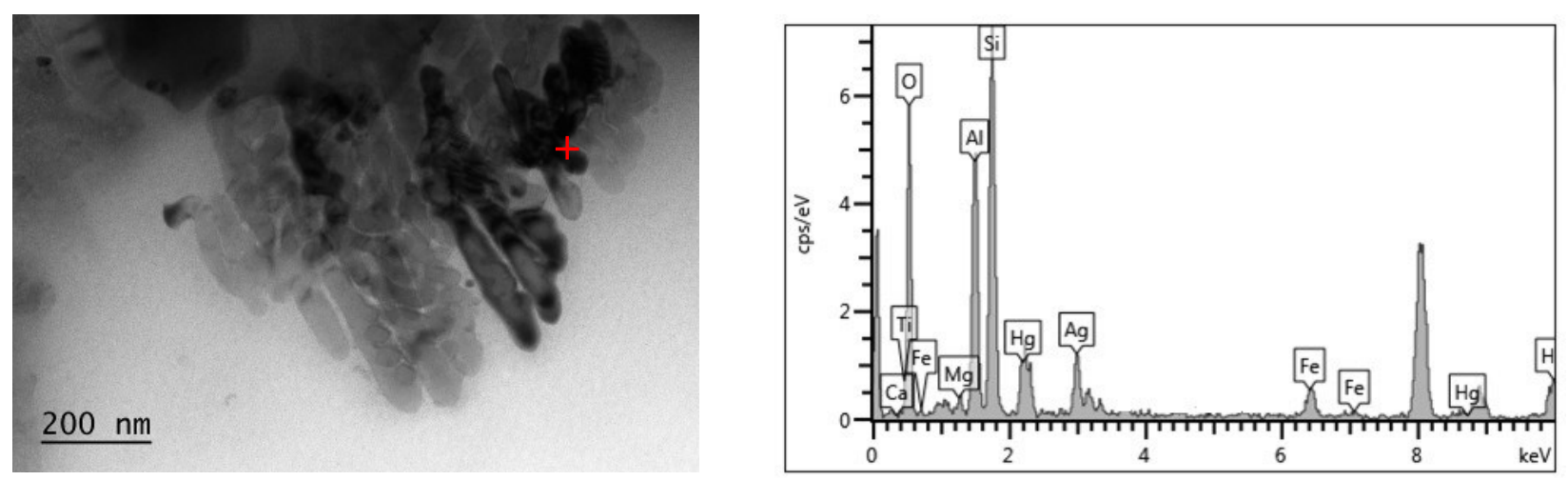

Fig. 6. TEM and EDX analysis of Ag-ZFA sample loaded with $\mathrm{Hg}$ (II) 


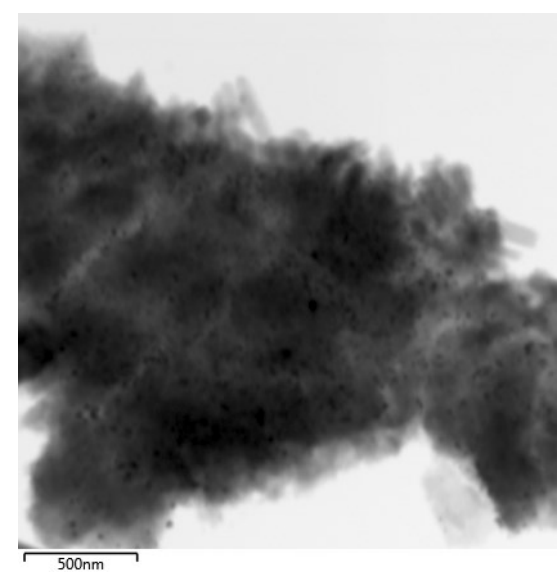

STEM micrograph

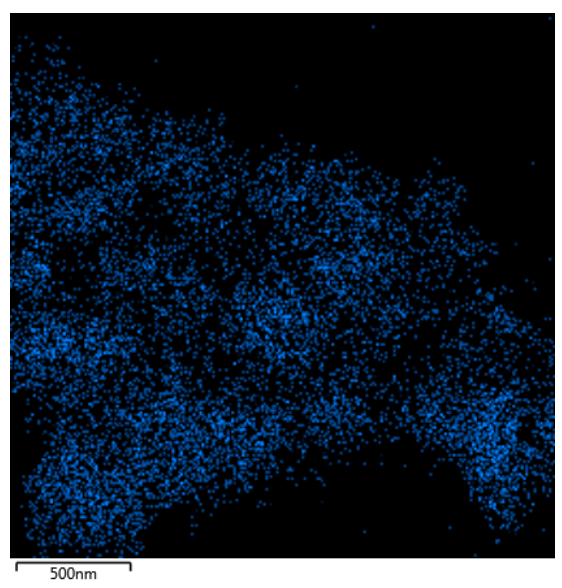

$\mathrm{Hg}-$ Mercury

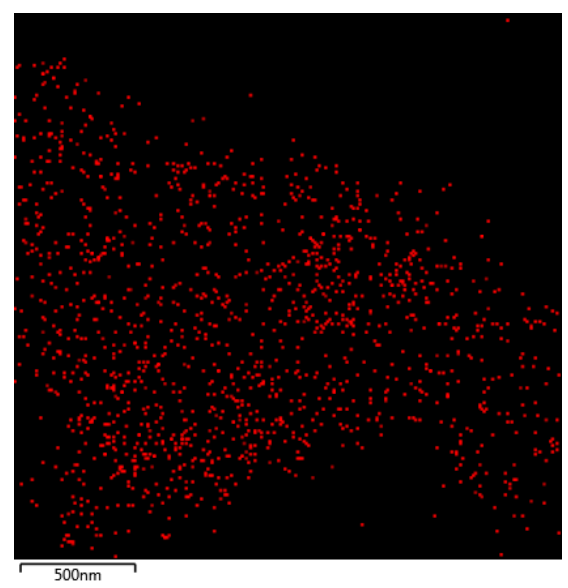

Ag-Silver

Fig. 7. TEM mapping of Ag-ZFA with $\mathrm{Hg}$ (II)

Another factor that possibly affects the $\mathrm{Hg}^{2+}$ removal is the surface charge of the materials. This can be studied by measuring their point of zero charge $\left(\mathrm{pH}_{\mathrm{ZPC}}\right)$, which determines the electrophoretic mobility where the net charge of the particle is zero. According to the results, the $\mathrm{pH}_{\mathrm{ZPC}}$ of ZFA and Ag-ZFA is about 4.5 (Fig. 8).
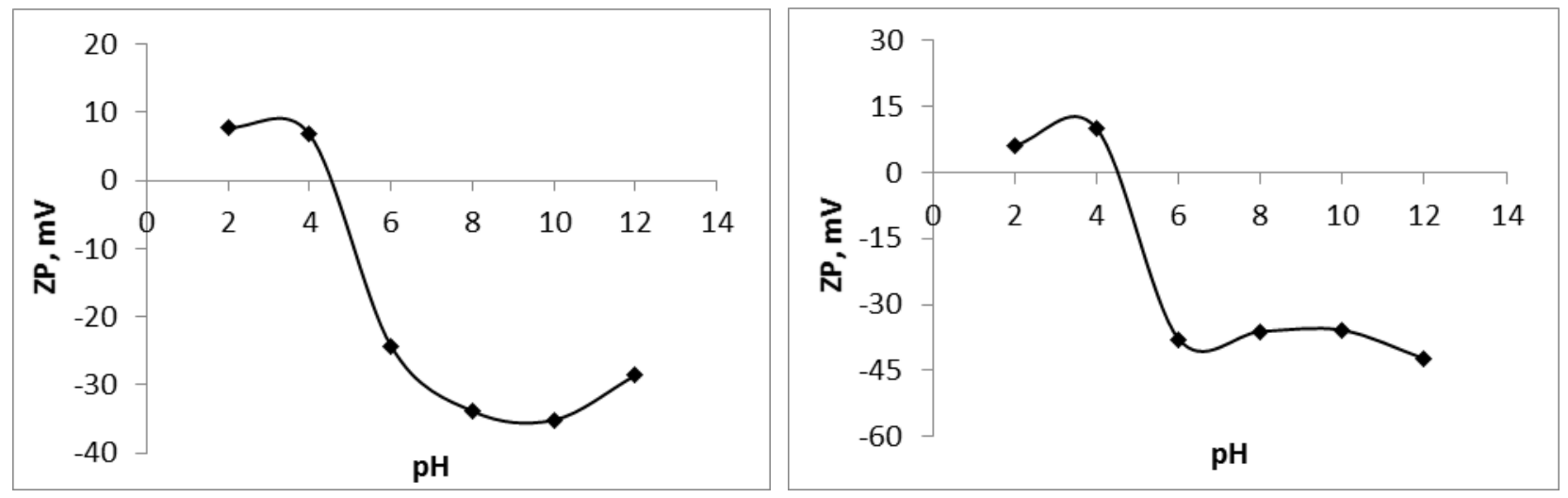

Fig. 8. Zeta potential values $(\mathrm{mV})$ at different $\mathrm{pH}$ : ZFA (left) and Ag-ZFA (right)

These data imply that at any $\mathrm{pH}$ lower than 4.5 , where most mercury is removed from solution, both materials have a positive surface charge that should repeal positively charged $\mathrm{Hg}^{2+}$ cations. However, an overlooked aspect in the related literature is the speciation of ions in solutions, especially in the presence of complexing agents such as $\mathrm{Cl}^{-}$ions. The speciation of the system studied is presented in Fig. 9. Evidently, at the $\mathrm{pH}<4.5$ the predominant species is a neutral 
soluble $\mathrm{HgCl}_{2}$. Thus, the surface charge is not expected to affect the uptake of $\mathrm{Hg}$ species under these conditions.

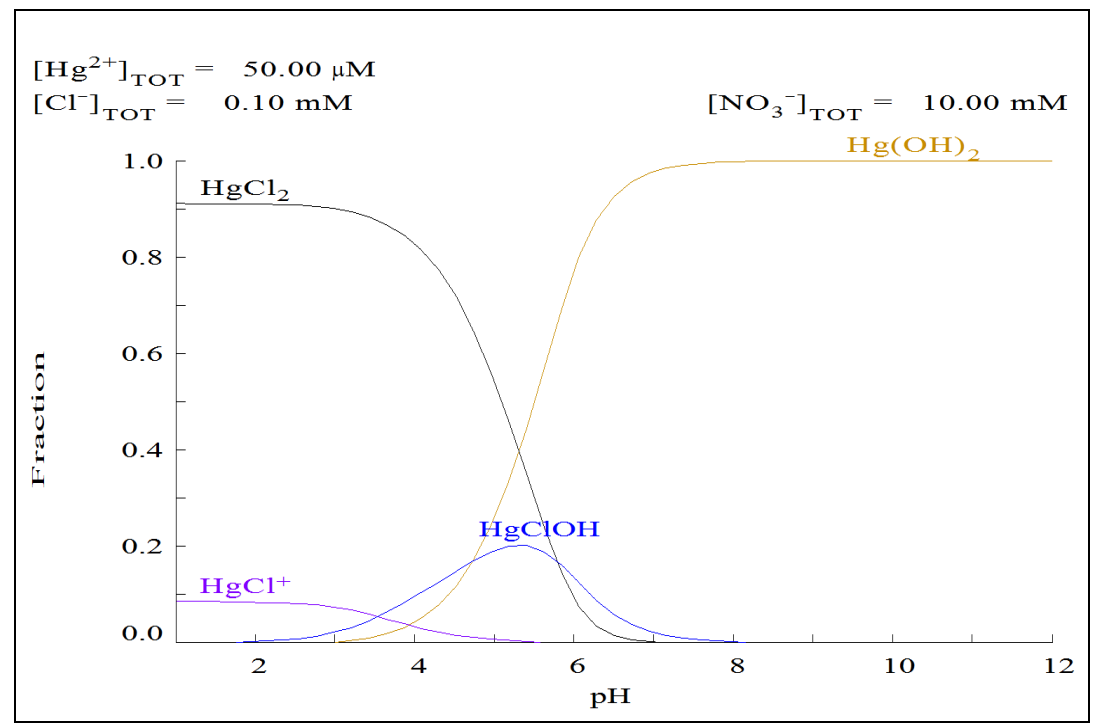

Fig. 9. Speciation of $10 \mathrm{~g} / \mathrm{m}^{3} \mathrm{Hg}^{2+}$ solution $\left(0.05 \mathrm{mmol} \mathrm{Hg}{ }^{2+}, 0.1 \mathrm{mmol} \mathrm{Cl}\right)$ [Diagram created by Medusa software]

\subsection{Leaching experiments and adsorption capacity}

It is important to study the leaching levels of adsorbed mercury since the ultimate goal of the research is to safely store the adsorbed metal in either an ionic state or an amalgam/alloy. According to the results, the Ag-ZFAs showed impressive storing capability, as the leaching of adsorbed $\mathrm{Hg}^{2+}$ is less than $1 \%$ in both strongly acidic and neutral conditions. The amount of leached $\mathrm{Hg}^{2+}$ is 4- to 8 -fold lower than in respective parent zeolite (Table 5).

Table 5. Leaching experiment of $\mathrm{Hg}^{2+}$ under strong acidic and neutral media ${ }^{\mathrm{a}}$

\begin{tabular}{lccc}
\hline \multicolumn{1}{c}{ Adsorbent type } & $\begin{array}{c}\text { Total } \\
\text { adsorbed Hg } \\
{[\mathrm{mg}]}\end{array}$ & $\begin{array}{c}\text { Leached Hg } \\
\text { after 12 d } \\
{[\mathrm{mg}]}\end{array}$ & $\begin{array}{c}\text { Leached Hg } \\
\text { after 12 d } \\
{[\%]}\end{array}$ \\
\hline CFA (pH 7.0) & 0.92 & 0.015 & 1.63 \\
CFA $(\mathrm{pH} \mathrm{2.0)}$ & 0.95 & 0.065 & 6.84 \\
ZFA (pH 7.0) & 6.06 & 0.195 & 3.22 \\
ZFA (pH 2.0) & 5.88 & 0.215 & 3.66 \\
R-ZFA (pH 7.0) & 4.25 & 0.230 & 5.41 \\
R-ZFA (pH 2.0) & 4.14 & 0.365 & 8.82 \\
Ag-ZFA (pH 7.0) & 7.69 & 0.060 & 0.78 \\
Ag-ZFA (pH 2.0) & 7.69 & 0.070 & 0.86 \\
\hline
\end{tabular}

${ }^{\mathrm{a}}$ The experimental conditions: $0.75 \mathrm{~g}$ of material in $50 \mathrm{~cm}^{3}$ of $150 \mathrm{~g} / \mathrm{m}^{3} \mathrm{HgCl}_{2}$ solution 
Similar studies were conducted in (Derkowski et al., 2006) where authors observed significantly higher leaching in CFAs compared to ZFAs. Hence, these silver NP-containing materials can be safely stored and utilized in natural systems, possibly with some pre-treatment. These results also support the hypothesized amalgamation mechanism in the nanocomposite material. Finally, the adsorption capacity of the zeolite and Ag-nanocomposite at $10 \mathrm{~g} / \mathrm{m}^{3}$ was measured to be 0.4 and 6 $\mathrm{mg} / \mathrm{g}$, respectively. The results reveal that the silver-containing composite has a much higher adsorption capacity than the parent zeolite.

\section{Conclusions}

The novel CFA-derived nanocomposite with Ag NPs in the range of 5 and $40 \mathrm{~nm}$, its parent K-CFA and synthetic zeolite K-ZFA were successfully applied for $\mathrm{Hg}^{2+}$ removal from water. The adsorption kinetics of $\mathrm{Hg}^{2+}$ on K-ZFA, Ag-ZFA and respective reduced material R-ZFA has shown that the nanocomposite demonstrate a strong $(<99 \%)$ and fast adsorption $(<24 \mathrm{~h})$ compared with parent KZFA and K-CFA. The characterization on XRD, TEM/EDX and mapping of post-adsorption materials has shown that the dominating mechanisms of mercury uptake in zeolites is physical adsorption, whereas in nanocomposites a combination of adsorption, redox reaction producing $\mathrm{Hg}^{\circ}$ and finaly amalgamation take place. The hypothesis of amalgamation reaction explains the superiority of the nanocomposite and is supported by the leaching experiments as well. This preliminary study demonstrated the ability of the fly ash derived nanocomposite to remove $\mathrm{Hg}^{2+}$ from water at relatively low loading of Ag NPs. The removal is much faster and leachability much less than this of the parent zeolite justifying the use of silver in the nanocomposite. Nevertheless, further experiments are needed in order to better understand the mechanism of $\mathrm{Hg}^{2+}$ uptake and evaluate the costs and benefits of using Ag NPs in CFA-derived nanocomposite materials.

\section{Acknowledgements}


The authors would like to acknowledge the Ministry of Education and Science of Kazakhstan and Nazarbayev University Research Council for funding the project entitled "Hyperstoichiometry Activity in Metal Nanoparticle Interaction" (HyperActiv), and the Royal Academy of Engineering (UK) for their financial and research support of the project IAPP/1516/13. We thank Oskemen city power plant for generously providing coal fly ash samples to carry out this research work.

\section{References}

Abbas, K., Znad, H., Awual, M.R., 2018. A ligand anchored conjugate adsorbent for effective mercury(II) detection and removal from aqueous media. Chem. Eng. J. 334, 432-443. https://doi.org/10.1016/j.cej.2017.10.054

AMAP/UNEP, 2013. Technical Background Report for the Global Mercury Assessment. Arct. Monit. Assess. Program. Oslo, Norway. 263.

Atkins, P., Paula, J. De, 2009. Atkins' Physical chemistry 8th edition. Chemistry (Easton). https://doi.org/10.1021/ed056pA260.1

Attari, M., Bukhari, S.S., Kazemian, H., Rohani, S., 2017. A low-cost adsorbent from coal fly ash for mercury removal from industrial wastewater. J. Environ. Chem. Eng. 5, 391-399. https://doi.org/10.1016/j.jece.2016.12.014

Azimi, A., Azari, A., Rezakazemi, M., Ansarpour, M., 2017. Removal of Heavy Metals from Industrial Wastewaters: A Review. ChemBioEng Rev. 4, 37-59. https://doi.org/10.1002/cben.201600010 
Belviso, C., 2017. State-of-the-art applications of fly ash from coal and biomass: A focus on zeolite synthesis processes and issues. Prog. Energy Combust. Sci. 000, 1-27. https://doi.org/10.1016/j.pecs.2017.10.004

Blissett, R.S., Rowson, N.A., 2012. A review of the multi-component utilisation of coal fly ash. Fuel 97, 1-23. https://doi.org/10.1016/j.fuel.2012.03.024

Bukhari, S.S., Behin, J., Kazemian, H., Rohani, S., 2015. Conversion of coal fly ash to zeolite utilizing microwave and ultrasound energies: A review. Fuel 140, 250-266. https://doi.org/10.1016/j.fuel.2014.09.077

Czarna, D., Baran, P., Kunecki, P., Panek, R., Żmuda, R., Wdowin, M., 2016. Synthetic zeolites as potential sorbents of mercury from wastewater occurring during wet FGD processes of flue gas. J. Clean. Prod. 172, 2636-2645. https://doi.org/10.1016/j.jclepro.2017.11.147

Deng, L., Li, Y., Yan, X., Xiao, J., Ma, C., Zheng, J., Liu, S., Yang, R., 2015. Ultrasensitive and highly selective detection of bioaccumulation of methyl-mercury in fish samples via ag0/hg0amalgamation. Anal. Chem. 87, 2452-2458. https://doi.org/10.1021/ac504538v

Derkowski, A., Franus, W., Beran, E., Czímerová, A., 2006. Properties and potential applications of zeolitic materials produced from fly ash using simple method of synthesis. Powder Technol. 166, 47-54. https://doi.org/10.1016/j.powtec.2006.05.004

Dos Santos, M.B.P., Leal, K.Z., Oliveira, F.J.S., Sella, S.M., Vieira, M.D., Marques, E.M.D., Gomes, V.A.C., 2015. Efficient removal of mercury from aqueous solutions and industrial effluent. J. Environ. Sci. Heal. Part A 50, 1230-1240. https://doi.org/10.1080/10934529.2015.1055147

Franus, M., Wdowin, M., Bandura, L., Franus, W., 2015. Removal of environmental pollutions using zeolites from fly ash: A review. Fresenius Environ. Bull. 24, 854-866.

Franus, W., 2012. Characterization of X-type zeolite prepared from coal fly ash. Polish J. Environ. Stud. 21, $337-343$.

Golubeva, O.Y., Ul'yanova, N.Y., Kurilenko, L.N., 2013. Synthesis and study of catalytic activity of zeolite Rho with varying content of silver nanoparticles. Glas. Phys. Chem. 39, 649-653. https://doi.org/Doi $10.1134 / \mathrm{S} 1087659613060047$

Goscianska, J., Ptaszkowska-Koniarz, M., Frankowski, M., Franus, M., Panek, R., Franus, W., 2018. Removal of phosphate from water by lanthanum-modified zeolites obtained from fly ash. J. Colloid Interface Sci. 513, 72-81. https://doi.org/10.1016/j.jcis.2017.11.003

Henglein, A., 1998. Colloidal silver nanoparticles: photochemical preparation and interaction with $\mathrm{O} 2$, CCl4, and some metal ions. Chem. Mater. 2, 444-450.

Henglein, A., Brancewicz, C., 1997. Absorption spectra and reactions of colloidal bimetallic nanoparticles containing 
mercury. Chem. Mater. 4756, 2164-2167.

Inglezakis, V.J., Loizidou, M.D., Grigoropoulou, H.P., 2002. Equilibrium and kinetic ion exchange studies of Pb2+, Cr3+, Fe3+ and Cu2+ on natural clinoptilolite. Water Res. 36, 2784-2792. https://doi.org/10.1016/S00431354(01)00504-8

Jha, B., Singh, D.N., 2014. A three step process for purification of fly ash zeolites by hydrothermal treatment. Appl. Clay Sci. https://doi.org/10.1016/j.clay.2013.12.035

Liu, W., Zhao, X., Wang, T., Fu, J., Ni, J., 2015. Selective and irreversible adsorption of mercury( ii ) from aqueous solution by a flower-like titanate nanomaterial. J. Mater. Chem. A 3, 17676-17684. https://doi.org/10.1039/C5TA04521E

Liu, Z., Yang, W., Xu, W., Liu, Y., 2018. Removal of Elemental Mercury by Bio-chars Derived from Seaweed Impregnated with Potassium lodine. Chem. Eng. J. https://doi.org/10.1016/j.cej.2018.01.148

Meena, A.K., Mishra, G.K., Kumar, S., Rajagopal, C., 2004. Low Cost Adsorbents for the Removal of Mercury (II) from Aqueous Solution- A Comparative Study. Def. Sci. J. 54, 537-548.

Pang, J.T.T., Ritchie, I.M., 1982. The reactions between mercury ions and silver: dissolution and displacements. Electrochim. Acta 27, 683-689. https://doi.org/10.1016/0013-4686(82)85060-3

Panichev, N., Kalumba, M.M., Mandiwana, K.L., 2014. Solid phase extraction of trace amount of mercury from natural waters on silver and gold nanoparticles. Anal. Chim. Acta 813, 56-62. https://doi.org/10.1016/j.aca.2014.01.011

Qu, Z., Fang, L., Chen, D., Xu, H., Yan, N., 2017. Effective and regenerable Ag/graphene adsorbent for Hg(II) removal from aqueous solution. Fuel 203, 128-134. https://doi.org/10.1016/j.fuel.2017.04.105

Rahbar, N., Jahangiri, A., Boumi, S., Khodayar, M.J., 2014. Mercury removal from aqueous solutions with chitosancoated magnetite nanoparticles optimized using the box-behnken design. Jundishapur J. Nat. Pharm. Prod. 9.

Shao, H., Liu, X., Zhou, Z., Zhao, B., Chen, Z., Xu, M., 2016. Elemental mercury removal using a novel KI modified bentonite supported by starch sorbent. Chem. Eng. J. 291, 306-316. https://doi.org/10.1016/j.cej.2016.01.090

Sumesh, E., Bootharaju, M.S., Anshup, Pradeep, T., 2011. A practical silver nanoparticle-based adsorbent for the removal of Hg2+ from water. J. Hazard. Mater. 189, 450-457. https://doi.org/10.1016/j.jhazmat.2011.02.061

Tauanov, Z., Shah, D., Itskos, G., Inglezakis, V., 2017. Optimized Production of Coal Fly Ash Derived Synthetic Zeolites for Mercury Removal from Wastewater. IOP Conf. Ser. Mater. Sci. Eng. 230. https://doi.org/10.1088/1757$899 X / 230 / 1 / 012044$

The European Parlament and the Council of the European Union, 2013. Directives of 12 August 2013 amending Directives 2000/60/EC and 2008/105/EC as regards priority substances in the field of water policy. Off. J. Eur. 
Union 2013, 1-17. https://doi.org/http://eur-lex.europa.eu/legal-content/EN/TXT/?uri=celex:32013L0039

Wang, J., Li, D., Ju, F., Han, L., Chang, L., Bao, W., 2015. Supercritical hydrothermal synthesis of zeolites from coal fly ash for mercury removal from coal derived gas. Fuel Process. Technol. 136, 96-105. https://doi.org/10.1016/j.fuproc.2014.10.020

Wdowin, M., Franus, M., Panek, R., Badura, L., Franus, W., 2014a. The conversion technology of fly ash into zeolites. Clean Technol. Environ. Policy 16, 1217-1223. https://doi.org/10.1007/s10098-014-0719-6

Wdowin, M., Macherzyński, M., Panek, R., Górecki, J., Franus, W., 2015. Investigation of the sorption of mercury vapour from exhaust gas by an Ag-X zeolite. Clay Miner. 50, 31-40. https://doi.org/10.1180/claymin.2015.050.1.04

Wdowin, M., Wiatros-Motyka, M.M., Panek, R., Stevens, L.A., Franus, W., Snape, C.E., 2014b. Experimental study of mercury removal from exhaust gases. Fuel 128, 451-457. https://doi.org/10.1016/j.fuel.2014.03.041

World Coal Institute, 2005. the Coal Resource a Comprehensive Overview of Coal the Coal Resource Where Does Coal Come From ? What Is It. World Coal Inst. 1-44. https://doi.org/10.1017/CBO9781107415324.004

Yang, W., Hussain, A., Zhang, J., Liu, Y., 2018. Removal of Elemental Mercury from Flue Gas Using Red Mud Impregnated by KBr and KI Reagent. Chem. Eng. J. https://doi.org/10.1016/j.cej.2018.02.023

Yao, Z.T., Ji, X.S., Sarker, P.K., Tang, J.H., Ge, L.Q., Xia, M.S., Xi, Y.Q., 2015. A comprehensive review on the applications of coal fly ash. Earth-Science Rev. 141, 105-121. https://doi.org/10.1016/j.earscirev.2014.11.016

Yu, J.G., Yue, B.Y., Wu, X.W., Liu, Q., Jiao, F.P., Jiang, X.Y., Chen, X.Q., 2016. Removal of mercury by adsorption: a review. Environ. Sci. Pollut. Res. 23, 5056-5076. https://doi.org/10.1007/s11356-015-5880-x

Zhang, F.-S., Nriagu, J.O., Itoh, H., 2005. Mercury removal from water using activated carbons derived from organic sewage sludge. Water Res. 391. Zhang, 389-395. https://doi.org/https://doi.org/10.1016/j.watres.2004.09.027

Zhang, J., Fidalgo, B., Kolios, A., Shen, D., Gu, S., 2018a. Mechanism of deoxygenation in anisole decomposition over single-metal loaded HZSM-5: Experimental study. Chem. Eng. J. 336, $211-222$. https://doi.org/10.1016/j.cej.2017.11.128

Zhang, J., Rao, C., Peng, H., Peng, C., Zhang, L., Xu, X., Liu, W., Wang, Z., Zhang, N., Wang, X., 2018. Enhanced toluene combustion performance over Pt loaded hierarchical porous MOR zeolite. Chem. Eng. J. 334, 10-18. https://doi.org/10.1016/j.cej.2017.10.017 